\title{
Variety and volume dynamic management for value creation in changeable manufacturing systems
}

\author{
Ahmed M. Deif ${ }^{a *}$ and Hoda A. ElMaraghy \\ ${ }^{a}$ Industrial Tachnology and Packaging Department, California Polytachnic State University, San Luis Obispo, CA, USA; ${ }^{b}$ Industrial \\ and Manufacturing Systems Engineering Department, University of Windsor, Windsor, ON, Canada
}

\begin{abstract}
In today's uncertain market and continuously evolving tochnology, managing manufacturing systerns are more complex than ever. This paper studies the dynamics of managing variety and volume to enhance value creation in manufacturers implementing system level advanced and automated manufacturing technology (AAMI). The demand is composed of heterogeneous customers who make purchasing decisions depending on the variety levels and lead times of the firm's product offerings. The cost structure adopted calculates profit as the difference between customer value creation rate (VCR) and costs associated with the process of creating this value. Reported results contribute to the variety and volume management literature by offering analytical clarity of factors affecting product platforms and capacity scalability man agement for systems with AAMT. In addition, insightful answers to the trade offs between profit maximising market coverage and investments, smoothing dernand policies and system stability for this type of environment are presented. Furthermore, the value of market information in deciding the industrial technology investment and also the impact of product life cycle on the same investment is captured.
\end{abstract}

Keywords: variety management; dynamic analysis; value creation; capacity scalability; advanced technology

\section{Introduction}

With the conscious evolution of market and technology, manufacturing systems have been always characterised by their variety handling and volume management capabilities. Classical dedicated systems were designed to enable high volume production with minimal variety of products, while more recent systems like flexible manufacturing systems (FMS) were developed to manage less volume but wider range of variety within a product family. Most recently, reconfigurable and changeable systems were introduced to manage different volume and variety levels when needed and where needed. This improvement in efficiency is a result of new system-level advanced and automated manufacturing technology (AAMT) development such as flexible product platforms designs, scalable systems, modular machine technology and standard interfaces between modules as well as function-oriented control architectures to enable plug and produce change scenarios. To understand the context of this study within AAMT, a brief overview of product platform and scalable capacity technology is presented first.

Product platforms in changeable systems are defined as the core collection of parts and product variants designs shared by members of product families (ElMaraghy et al. 2013, 2011). Process platforms or production-based platforms (Jiao, Simpson, and Siddique 2007) are used to process product variants by focusing on common design features or components and also the common core processing technology and stations used to manufacture the core (platform) of product variants. Product/process platforms can be seen as the evolution of cellular manufacturing, with more complex layout and a system design that is well-integrated with the product architecture (Hu et al. 2011). An important challenge is not only to design the product family, but also to simultaneously design its production processes and manufacturing/ assembly system. Once functional entities of the product are identified, the corresponding production system, which is often complex due to the multitude of product variants, is designed. By using AAMT technology of product platforms with identical core components (engine, suspension, gearboxes, and so on) across different car types, Volkswagen (VW) saved hundreds of millions of dollars and gained the largest market share in Europe (Miller 1999). Three types of product platforms exist in manufacturing: scalable platforms, in which variants can be produced through shrinkage or extension of scalable variables; modular platforms, which enable product differentiation through adding/removing/substituting

\footnotetext{
*Corresponding author. Email: adeif@calpoly.edu
} 
different modules; and generational platforms, in which possible requirements for changing the design over a period of time are considered to allow variation of next generations (Jiao, Simpson, and Siddique 2007).

Capacity scalability is another example of system-level AAMT. It can be defined as the ability to adjust the production capacity of a system through system reconfiguration and adaptation with minimal cost in minimal time over a large capacity range with given and/or variable capacity increments (Spicer et al. 2002). ElMaraghy (2005) explains the dimensions of capacity scalability in AAMT by identifying and classifying the scalability characteristics into 'physical scalability' and 'logical scalability' attributes. Examples of physical capacity scalability enablers include the adding or removing machines, machine modules, such as axes of motions or heads, as well as tools or other components. Examples of logical capacity scalability enablers include increasing or decreasing the number of shifts or the number of workers as well as outsourcing.

Offering product variety and responding to changing production volumes can help firms to better match customer's preferences and increase their market share in today's heterogeneous consumer markets. However, offering wide scope of product variants and dynamic volume response are costly to produce and reduces economies of scale while the incremental sales volume and market share lead to increase of operations and logistics expenses. The variety paradox (ElMaraghy et al. 2013) is that increased variety does not always guarantee more sales or market shares. Hence, the optimal strategy regarding the product variety and volume should be viewed more and more from a value creation perspective to ensure the optimal setting of variety and volume management in AAMT systems.

Value creation can be attributed to profitability of the organisation and its continuous grow of (internal value), or to catering for the customer needs of price, service, and image (external value) (Martínez-Olvera and Davizon-Castillo 2015). In this research, we define value from customer (external) perspective, but at the same time relate that value to the profitability of the manufacturer. More specifically, value generation in the considered AAMT systems depends on efficient variety-based offerings at timely manner in order to fulfil customer's value utility function. Variety and lead time offered by AAMT in changeable systems can increase perceived benefits for customers expecting to receive a product with closer fit to their individual requirements (Jianxin and Tseng 2000).

A dynamic model for a changeable manufacturing system which adopts AAMT like product platform technology to manage product variety scope and also implements dynamic scalable capacity to manage production volume level variations is presented. The profit generated is the primary performance measure of the modelled system. However, the costing approach is based on customer value generation by capturing customer valuation requirements rather than using classical accounting techniques; to better respond to today's heterogeneous demand. The proposed model enhances the understanding of the factors affecting managing product platforms and production capacity scalability in changeable manufacturing systems, and helps managers in deciding on the trade-offs between profit maximising and investments in AAMT capital and scalable lines for uncertain and heterogeneous consumer markets. The aim is to maximise the potential gains by offering appropriate range of product(s) variants and minimises lost sales opportunities for not offering product variants in the right quantities and within the right time window.

\section{Literature review}

Variety and production volume in manufacturing systems has been in most cases managed separately. This review focuses on how each problem was modelled and managed and also the used cost models and then briefly reviews system dynamics (SD) approaches adopted to combine modelling and managing production volume and product variety.

Setting an optimal product variety strategy, mainly in the marketing and economics literature, has been extensively researched. Variety management has been primarily based on models of vertical differentiation of substitute products and models of product lines design with associated pricing decisions in order to effectively extract customer surplus. Examples of these models include the early work of (Mussa and Rosen 1978) and (Vandenbosch and Weinberg 1995) and more recently the work of ( $\mathrm{Yu}$ 2012) who considered the same models with some batch production planning aspects. Some researchers have taken a more cross-functional approach focusing on the conflict between the implications of commonality on costs (i.e. operations perspective) and on reduced product differentiation and sales (i.e. marketing perspective). Examples include (Kim and Chhajed 2000) who studied the trade-off between cost savings and losses due to reduced product differentiation resulting from component commonality. Desai et al. (2001) focused on the trade-off between revenue losses resulting from reduced product differentiation and cost savings achieved through design effort. However, (Ramdas 2003) in reviewing product variety management literature using vertical differentiation models found that these models focus on narrow trade-offs within functional silos ignoring important interdependencies across decisions such as volume levelling and enabling technologies. Another extensive review of models and metrics that address product platforms can be found in (Jiao, Simpson, and Siddique 2007). 
Production volume management, especially in changeable systems, follows dynamic capacity scalability approaches. Classical capacity and volume management literature is extensively reviewed by (Manne 1967) and (Luss 1982). In the context of changeable and reconfigurable systems, (Asl and Ulsoy 2002) presented a dynamic approach to capacity scalability modelling based on the use of feedback control. Suboptimal solutions which are robust against demand variations and partially minimise the cost of capacity scalability were presented. In Deif and ElMaraghy (2006), a dynamic model for capacity scalability for Reconfigurable Manufacturing Systems was developed and analysed based on control theoretic approaches to find the best design of the scalability controller. Deif and ElMaraghy investigated a new hybrid scaling policy taking into account demand, work-in-process and backlog levels in single stage production and with uncertainties in multi-stage production in Deif and ElMaraghy (2007, 2009), respectively. Spicer, Yip-Hoi, and Koren (2005) explored the type of the scalability instrument to be employed as well as whether or not to employ scalability as a basis for analysing alternative solutions. Matta et al. (2008) developed a model for managing capacity scalability taking into account various technological preferences the market may require. An extensive review of modern capacity scalability problem and its management can be found in Putnik et al. (2013).

In addition, the cost structure in many of the variety management models is mainly formulated as quality-dependent fixed cost or variable cost which is typically simplified as a constant or a convex increasing function (e.g. Choudhary et al. 2005; Matsubayashi et al. 2009). Few researchers considered product development cost as a set-up cost when making product design decisions such as Krishnan and Zhu (2006) and Jones and Mendelson (2011). In considering production volume management, costing was based on capturing the overall cost of production versus the profit generated by selling the produced mix of products using conventional accounting approaches over the life of the system (see for e.g. (Ross, Rhodes, and Hastings 2008) for cost modelling of capacity scalability in changeable systems). However, in today's heterogeneous market revenues should be captured as a function of generating value to the very selective global customer as well as the cost of technologies which enable such creation. The few value-based cost models used in variety and volume management include the work of Agyapong-Kodua and Weston (2011) who used SD to capture salient factors which induce dynamics in manufacturing systems and related them to cost and value generation in classical production system. Piller and Salvador (2013) developed a framework to calculate value generated by manufacturing systems as the difference between the gross utility and both the acquisition cost and evaluation search cost. They related value creation to different strategic capabilites of an organization. Lopez and Arbos (2013) provided evidence of potential problems with using transaction-based cost accounting techniques in lean systems and proposed value stream costing based on the known VSM as a better approach for lean manufacturing costing.

Finally, modelling and controlling complexities of variety and volume management problem with conventional methods is becoming more difficult given the high level of uncertainty governing external (e.g. market stochastic behaviour) and internal (e.g. advanced technology) manufacturing environment. Typical static formulation of the product variety and production volume management is no longer suitable and thus dynamic approaches are preferred to capture and handle the associated complexities. Dynamic approaches include control-theoretic models such as those used by Duffie (2014) who studied the effect of capacity disturbances and capacity delays on system performance in multiple workstations; and (Wikner, Naim, and Rudberg 2007) who modified the automatic pipeline inventory and order-based production control system used for make-to-stock to deal with make-to-order systems using the dynamic surplus capacity. Fluid dynamics is another dynamic approach for variety management in supply chain as proposed by Marufuzzaman and Deif (2010). SD is another well-known approach used to handle the dynamic modelling of manufacturing systems like the work by Goncalves, Hines, and Sterman (2005), Vlachos, Georgiadis, and Iakovou (2007) and Khataie and Bulgak (2013) who used it to model various capacity, quality and reliability problems. Literature shows that SD techniques offer a unique approach towards the modelling of complexities and dynamics in systems (Wolstenholme 1999; Sterman 2000). They are able to capture factors or elements which induce dynamics in manufacturing systems.

Based on the previous analysis, a dynamic model that captures both variety as well as volume management in today's changeable systems and employs value-based costing approach is needed. The model would act as an analysis and decision-making tool to better understand and optimally manage decisions involving marketing polices, internal technologies investment, system's settings and efficient demand capturing levels. The approach and analysis presented in the next sections respond to this need.

\section{Dynamic variety and volume management model}

A dynamic model for the variety and volume management problem in changeable manufacturing systems with its different AAMT internal and external parameters has been formulated using SD and is depicted in (Figure 1).

The proposed model, which captures the market heterogeneous demand information, is composed of two main subsystems. The first subsystem is geared towards responding to the demand for variety scope by adopting product 


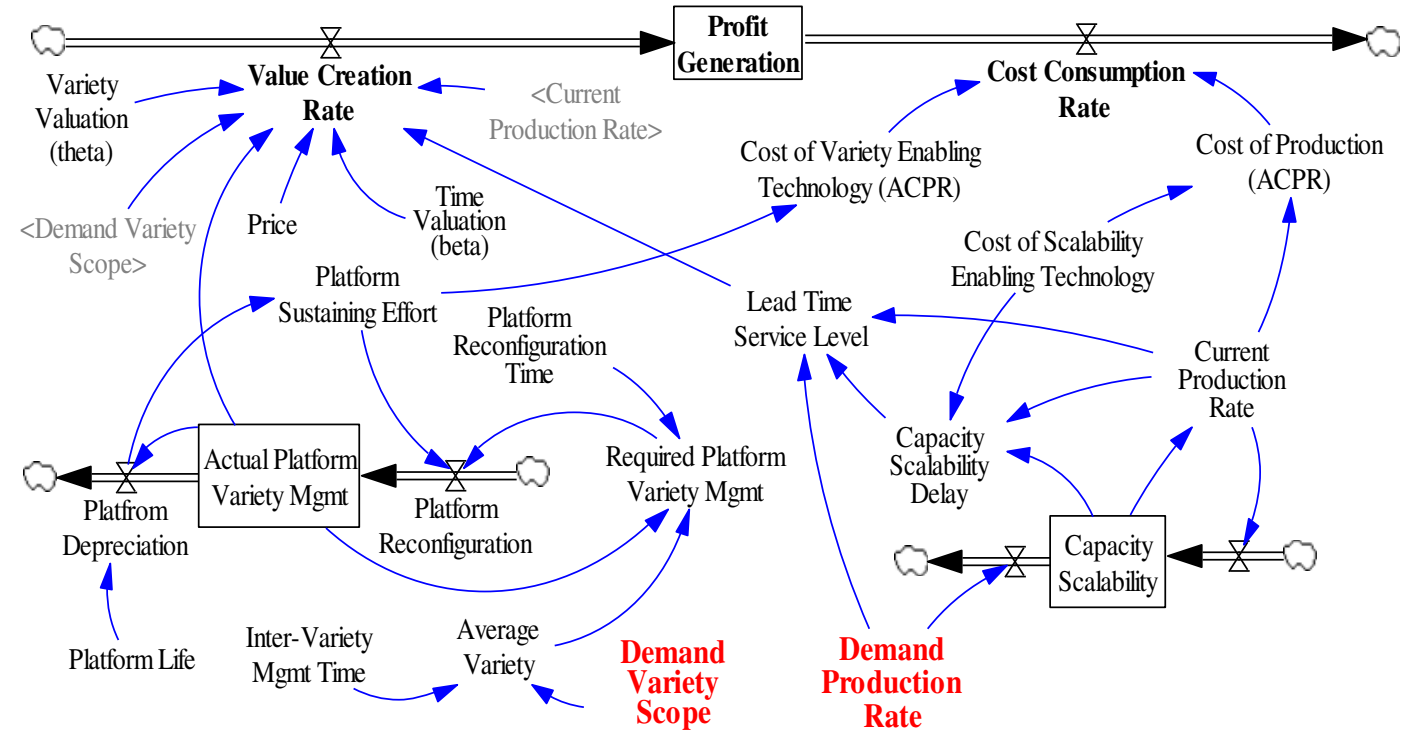

Figure 1. Dynamic variety and volume management model in changeable system.

platforms with their associated factors such as reconfiguration time, sustaining effort and depreciation life time. The second subsystem is focused on responding to the required production volume level of demanded product variants using a scalable production capacity system with its scalability delay time. The costs of the AAMT enabling technologies used to achieve the objectives of these two subsystems are captured using activity-based costing (ABC) methods with various activity cost pooling rates (ACPR) which form the aggregated cost for responding to demand. The value created by a production scenario is captured through the market valuation of the system's response level to the required product variety scope and the production volume lead time. Finally, the profit is calculated as the key performance index of the developed model representing the difference between the generated value and the associated costs. The model can account for both deterministic and stochastic values (inputs) for the different parameters depending on the type of data available. The details of each subsystems and components are discussed in the following sections.

\subsection{Model notation and definition}

Table 1. Notations and definitions of the developed model's parameters.

\subsection{Model dynamics}

\subsubsection{Variety management system}

As mentioned earlier, the modelled system uses reconfigurable product platforms to manage the variety of products. The stream of demanded variety scope (DVS) is used to capture variety demand and is averaged using demand smoothing time (DST) to set the target average variety (AV) that the system will aim to manage (Equation (1)):

$$
\mathrm{AV}=\frac{\mathrm{DVS}}{\mathrm{DST}}
$$

The AV is further used to determine the required platform variety management (RPVM) level which the AAMT management will try to achieve using a goal adjustment control approach (sometimes referred to as goal seeking (Richardson 1996)). The adjustment is based on the difference between the AV target and the actual platform variety management (APVM) level and is delayed as function in the platform reconfiguration time (PRT). The PRT reflects the flexibility degree of the employed AAMT management when switching from one product variant to another. Equation (2) shows the modelled goal adjustment approach.

$$
\mathrm{RPVM}=\frac{\mathrm{AV}-\mathrm{APVM}}{\mathrm{PRT}}
$$


The APVM is calculated as the difference between platform reconfiguration rate (PRR) and the platform depreciation rate (PDR) as shown in Equation (3). This is another aspect of AAMT management in these systems.

$$
\operatorname{APVM}(t)=\operatorname{PDR}(t)-\operatorname{PRR}(t)
$$

PRR captures the required variety rate and further enhances it with platform sustaining effort (PSE) as shown in Equation (4). It is important to mention that such enhancement will come at a cost that will be further discussed in Section 3.2.3.

$$
\operatorname{PRR}(t)=\operatorname{RPVM}(t)+\operatorname{PSE}(t)
$$

PSE is an aggregate value that reflects the AAMT management effort to counter the effect of depreciation rate through AAMT maintenance, technology changes/upgrades, etc. In this model, a simple linear relation is used to relate the PSE to its depreciation rate (PDR) using the parameter $\alpha$ as expressed in Equation (5). Similar simple linear relation assumption like the one presented here is supported with some literature like in Boucekkine, del Rio, and Martinez (2009). The value of the $(\alpha)$ parameter depends on the type of platform employed (scalable, modular or generative). The value of $\alpha$ is assumed to be 1 in this model. However, further investigation of such linearity with each platform technology will be a subject for further research.

$$
\operatorname{PSE}(t)=\alpha \operatorname{PDR}(t)
$$

PDR is the rate by which the implemented product platform will depreciate over its platform life (PL) and is affected by the current production and actual performance of the platform (Equation 6 which is also supported with results in Boucekkine, del Rio and Martinez (2009). The value of PL is related to the product life, the technology implemented, investments plans as well as the firm's costing policy.

$$
\operatorname{PDR}(t)=\frac{\mathrm{APVM}}{\mathrm{PL}}
$$

\subsubsection{Volume management system}

The required production volume for each of the product variants is assumed to be equal (same order size). Thus, the volume of production managed (number of all product variants) is the aggregate sum of all orders. The current production rate (CPR) is supposed to fulfil the demand production rate (DPR). However, to accommodate for market dynamics, the system is equipped with scalable capacity systems to make up for any discrepancy between both rates through capacity scalability level (CSL). The scaling system calculates that discrepancy as a percentage of CPR. This production control mechanism is shown in Equations (7 and 8).

$$
\begin{aligned}
& \operatorname{CPR}(t)=\operatorname{CPR}\left(t_{0}\right)+\operatorname{CSL}(t) \\
& \operatorname{CSL}(t)=\frac{\operatorname{DPR}(t)-\operatorname{CPR}(t)}{\operatorname{CPR}(t)}
\end{aligned}
$$

The scalable capacity is introduced after a capacity scalability delay (CSD) time. In this model, the delay time is modelled as a proportion of the production lead time which is the same proportion of the scaled capacity rate to the CPR. This dynamic calculation of the (CSD) time will better capture real capacity scaling practices than the classical assumption of a constant (CSD) time (Matta, Tomasell, and Valente 2007). In addition and to further capture the dynamics of such delay time, (CSD) time is introduced as a function of the implemented scalability enabling technology. The adopted function in this model is consistent with the wide literature which supports that implementing technology can reduce the production time and cost (examples include De Groote 1994; Adner and Levinthal 2001). We follow the analogy of (Heese and Swaminathan 2006) who showed such reduction is a multiplicative function of the cost of technology and the work of Desai et al. (2001) who showed that similar function can be modelled as square root of the cost of such technology per produced part.

It is important to note that this reduction in the delay time using such technology will also come at a cost that will be further explained in Section 3.2.3. Capturing the dynamics of the CSD time in this manner is essential AAMT management since the overall lead time of production is an integral component in value creation for the customers and this lead time is highly affected by this delay. The CSD time calculation is shown in Equation (9).

$$
\operatorname{CSD}(t)=\left(\frac{\mathrm{CSL}}{\operatorname{CPR}(t)}\right)\left(\frac{1}{\operatorname{CPR}(t)}\right) *(1-\sqrt{ } \operatorname{CSET})
$$




\subsubsection{Profit generation calculations}

As mentioned earlier, in today's customer-centred market, profit generation (PG) should be captured as function of the value generated for the customers. Equation (10) depicts how profit is calculated in this analysis as the difference between the VCR to the customers and the costs consumption rate (CCR) associated with such creation.

$$
\operatorname{PG}(t)=\operatorname{Max}(\operatorname{VCR}(t)-\operatorname{CCR}(t), 0)
$$

The coming sections will detail how the value rate and the cost rate are calculated.

3.2.3.1 Value creation rate. Parameters $\theta$ and $\beta$ are used to represent the customer's preference on variety scope satisfaction and lead time service level (LTSL) of the required volume, respectively. It is assumed that $\theta$ and $\beta$ are stochastic variables with uniform distribution $[0,1]$ i.e. the customer's heterogeneity in the valuation of product variety and lead time is uniformly distributed among all arrivals. This assumption follows a common practice in existing economic literature that models customer income dispersion (Gabszewicz and Thisse 1979; Tirole 1988), which is also adopted by other research works (e.g. Choudhary et al. 2005; Chambers, Kouvelis, and Semple 2002)

Customers make their purchase decisions to maximise their utility of consumption or benefit which is defined as a linear function of the ratio of the APVM and the demand variety scope (DVS) to variety valuation parameter $\theta$ and also the LTSL value compared to the customer lead time valuation parameter $\beta$. Any customer who has the desired utility satisfied is willing to buy the product with price $(\mathrm{P})$. The linear utility function modelling will lead to a linear demand function which is not only widely adopted in literature, but also verified by empirical evidences (Schmidt and Porteus 2000; Yu 2012). The VCR that reflects this utility function is shown in Equation (11).

$$
\operatorname{VCR}(t):\left\{\begin{array}{l}
\text { If }: \operatorname{APVM} / \mathrm{DVS} \geq \theta \text { and LTSL } \geq \beta \\
\text { Then }: \operatorname{VCR}(t)=\mathrm{P} * \operatorname{CPR}(t) \\
\text { Else }: \operatorname{VCR}(t)=0
\end{array}\right.
$$

The LTSL reflects both the response to the required DPR and the time required for such response. Satisfying the required volume is captured as a relative measure between the required demand volume and the current production volume and that measure (which ideally should approach 1) is further decreased (penalised) by a value equal to the relative measure between capacity scaling delay time and production lead time (thus the faster the scaling the less the penalty will be).

$$
\mathrm{LTSL}=\operatorname{Max}\left[\left[\operatorname{Min}\left(\frac{\mathrm{CPR}}{\mathrm{DPR}}, 1\right)\right]-\frac{\mathrm{CSD}}{1 / \mathrm{CPR}}, 0\right]
$$

3.2.3.2 Cost consumption rate. The cost structure used to calculate the CCR is based on the concept of ABC introduced by Cooper and Kaplan (1991). ABC estimates the product/service cost by assigning cost to the activities involved in their creation process. Park and Simpson (2008) stated that ABC systems are appropriate costing methods for product families and product platforms. These activities can be distributed among produced units or batch or process. In managerial accounting, activity cost pool rate is a set of costs incurred when certain operations are performed within the organisation. By accounting for all costs incurred in a specific activity using ACPR, it becomes simpler to assign those costs to products, batch or process and obtain an accurate estimate of production costs (see Table 1).

The CCR is mainly composed of three components. The first component is the product unit cost (PUC) reflecting the pooled cost of materials, labour and other overheads and it is distributed over the produced parts. The second considered cost is pooled over the process of sustaining the AAMT product platforms discussed earlier and is referred to as the cost of variety enabling technology (CVET). It is important to emphasise that CVET will be highly affected by the type of platforms used (scalable, modular or generative). The final cost component is the AAMT cost accounting for the cost of scalability enabling technology (CSET) and it is distributed over produced parts. CCR are in Equations (13) and (14).

$$
\begin{gathered}
\operatorname{CVET}(t)=\operatorname{PSE}(t) * \operatorname{ACPR}_{\mathrm{CVET}} \\
\operatorname{CCR}(t)=\operatorname{CVET}(t)+\left[\operatorname{CPR}(t) *\left(\mathrm{ACPR}_{\mathrm{PUC}}+\operatorname{ACPR}_{\mathrm{CSET}}\right)\right]
\end{gathered}
$$




\section{Investigating AAMT management policies in changeable systems}

To illustrate the developed dynamic variety and volume AAMT management system model, a case study of a furniture manufacturer (where much of the data is adopted from Suzić et al. (2012) is considered. The data gathered is suitable for the purpose of this research since the selected case study represents an industry that strives to maintain appropriate levels of both variety (different furniture models) as well as dynamic volumes (depending on seasons and market trends). The values within the parametric analysis presented in this section is based on both the case study data for the parameters similar to the proposed model as well as extending these values to explore different market and internal system scenarios. This parametric variation (within a limited feasible practical ranges) will highlight different policy options for AAMT system management against these internal and external scenarios. It is also important to mention that the adopted case study utilises an FMS to respond to changes in the required volume and variety scope; and that FMS is a special type of AAMT changeable systems which the developed model can represent. The company produces panel furniture with 40 different products belonging to five main product families and other kinds of smaller pieces of furniture for the household. The product families are small tables, chairs, night stands, small beds and clothing shelves. Flexible product platforms are implemented within two production cells. Flexible line and products similar to the adopted case study are shown in Figure 2 with examples from each of the five product families.

Production starts in each cell with the cutting of basic shapes of wood panels for future product parts. The cutting operation uses two cutting machines to single saw and the angular plant with intelligent trimming of the recuts. The next phase of production is edge finishing which uses three distinct flexible machines for panel edge finishing and bending. Next, parts go to the drilling operation which uses three point-to-point drilling machines. Further into the process, two CNC centres called flexible carving machines are used for complex shapes of parts. The production process is finalised using manual assembly followed by visual inspection of products, and then final control and packaging. Special machining is done on some parts where special features, such as mirrors for example are assembled on them using hold-down machines.

The company conducted market research to find out the preference and valuation (or expectation) of the customers in the region in order to best respond to their demands and maximise their values. The research revealed that the customers do value having at least $60 \%$ of their expected variety scope satisfied. In addition, customers expect at least $70 \%$ of the promised LTSL to be respected. Table 2 outlines data used in analysis of the case study. It is important to note that although the results reported from the following analysis applies mainly to the selected industry and similar manufacturers in terms of technology adopted and market conditions, however, many of the dynamic behaviours and explored

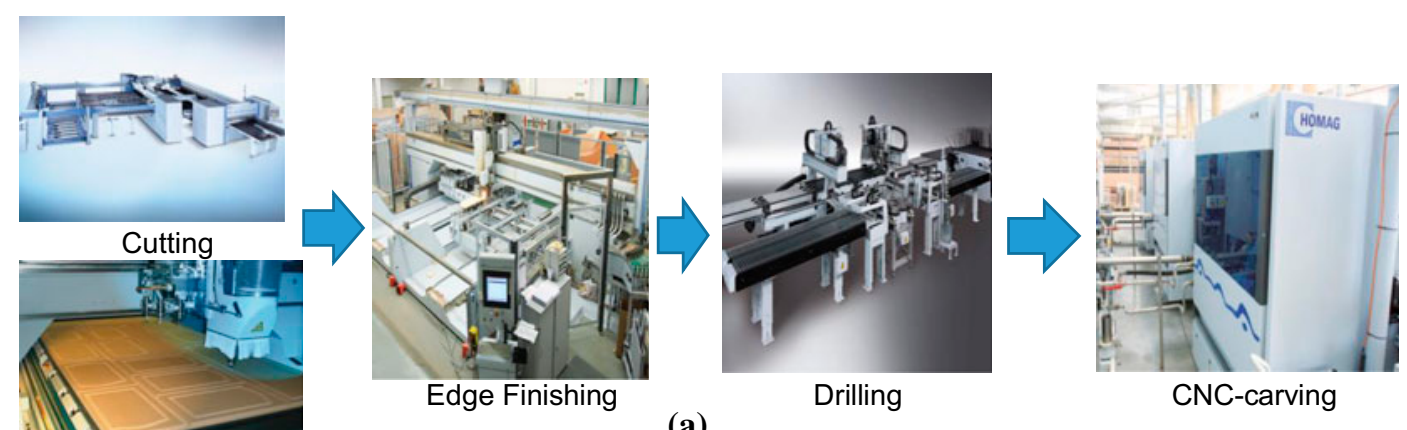

(a)

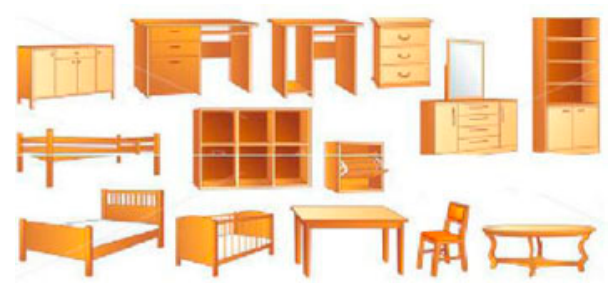

(b)

Figure 2. Panel furniture manufacturer (a) similar production layout (adopted from http://www.homag group.com/en en/products/solu tions/furniture production), (b) examples of produced product families (adopted from http://www.shutterstock.com). 
Table 1. Notations and definitions of the developed model's parameters.

\begin{tabular}{|c|c|c|}
\hline Notation & Definition & Description \\
\hline $\operatorname{CCR}(t)$ & Cost consumption rate & The accumulated cost rate required to deliver the required variety and volume \\
\hline CVET & $\begin{array}{l}\text { Cost of variety enabling } \\
\text { technology }\end{array}$ & The cost to operate and sustain production using product platforms (variety enabler) \\
\hline $\mathrm{CPR}(t)$ & Current production rate & The facility normal production rate \\
\hline PUC & Product unit cost & Cost of overhead, labour and material per produced product \\
\hline $\operatorname{PSE}(t)$ & Platform sustaining effort & $\begin{array}{l}\text { An aggregate value that reflects the cost of facility up keeping to counter the effect of } \\
\text { platform depreciation rate through maintenance, technology changes/upgrades }\end{array}$ \\
\hline LTSL & Lead time service level & $\begin{array}{l}\text { The response level to the required demand volume within the time required for such } \\
\text { response }\end{array}$ \\
\hline CSET & $\begin{array}{l}\text { Cost of scalability enabling } \\
\text { technology }\end{array}$ & $\begin{array}{l}\text { Cost required to successfully scale (up or down) the production capacity to meet the } \\
\text { required demand volume }\end{array}$ \\
\hline APVM & Actual platform variety level & The level of variety scope (number of variants) produced using product platform \\
\hline RPVM & $\begin{array}{l}\text { Required platform variety } \\
\text { level }\end{array}$ & The target variety scope that the product platform aims to produce \\
\hline $\mathrm{P}$ & Selling price & Price of the product to the customer \\
\hline $\operatorname{DPR}(t)$ & Demand production rate & The volume of products required by the market \\
\hline $\operatorname{VCR}(t)$ & Value creation rate & $\begin{array}{l}\text { This is the rate of creating value that will satisfy the customer expectations and will be } \\
\text { translated into revenue }\end{array}$ \\
\hline $\operatorname{CSD}(t)$ & Capacity scalability delay & Time required for the capacity to be scaled up/down including delivery $\&$ ramp up time \\
\hline DVS & Desired variety scope & The variety scope required by the market \\
\hline CSL & Capacity scalability level & $\begin{array}{l}\text { The actual scaled capacity level that will be added to the current production rate to meet } \\
\text { the demand volume. }\end{array}$ \\
\hline PG & Profit generation & $\begin{array}{l}\text { The difference between revenue gained by catering for the customer desired value and } \\
\text { costs used to generate such value }\end{array}$ \\
\hline PRT & Platform reconfiguration time & The time required to reconfigure the product platform to change the offered variants \\
\hline PL & Platform life & The expected platform life time \\
\hline AV & Average variety & The new target of variety scope after the demand has been smoothed over time \\
\hline $\operatorname{PDR}(t)$ & Platform depreciation rate & The depreciation rate of the platform which is related to the product life time \\
\hline $\operatorname{PRR}(t)$ & Platform reconfiguration rate & The rate by which the product platform is reconfigured to produce product variants \\
\hline DST & Demand smoothing time & $\begin{array}{l}\text { This is the factor used to smooth the required variety scope demand over an extended } \\
\text { period of time }\end{array}$ \\
\hline$\beta$ & Customer lead time valuation & Customer's preference (expectation) on lead time service level satisfaction \\
\hline$\theta$ & Customer variety valuation & Customer's preference on variety scope satisfaction \\
\hline
\end{tabular}

management policies can be used in its general context to other changeable systems adopting AAMT. This is mainly true since the objective of the proposed study and analysis is to offer insights on how demand variety and volume changes impose managerial challenges on AAMT systems in terms of their types and nature even if their magnitude will differ from one case to another.

\subsection{Impact of AAMT variety management marketing policy}

The first analysis in this study examines the impact of the adopted AAMT policy to manage the variety scope required by customers. In the developed model such policy is reflected in the DST used to smooth the DVS over a certain period. The smoothing decision is a practice usually followed by manufacturers to hedge against demand noise while fulfilling the required demand over a more relaxed period of time. In this analysis, it reflects the management approach to balance between fast responsiveness to desired variety scope and the cost and effort required to accomplish that.

Figure 3 shows the profit generated with different DST values. From the results shown and within the settings of the considered case study, highest profit generated over the simulated period was generated with DST value of 3 months. One would expect that the faster the system response to the desired variety (DST $=1$ in this case), the higher the profit would be as a result of high customer satisfaction level. However, this was not the case since such fast response increased the APVM level leading to higher cost as explained earlier. On the other hand, the highest profit was not generated with highest DST value considered $(\mathrm{DST}=4)$. These results highlight the required trade-off when setting a marketing policy to balance between fast response and the cost and effort associated with such response in AAMT variety managment. 
Table 2. Data for the analysis of the considered panel manufacturer case study.

\begin{tabular}{|c|c|c|}
\hline Parameter & Value & Comment \\
\hline Demand variant release rate 2 & 6 variants/month & Required variety scope (DVS) \\
\hline Demand volume rate (DPR) & 100 products/month & Average batch size for every variant \\
\hline Average selling price $(\mathrm{P})$ & $\$ 80 /$ product & \\
\hline $\begin{array}{l}\text { Customer lead time valuation } \\
\qquad(\beta)\end{array}$ & $\begin{array}{l}\text { Random Uniform }(0.6 \text {, } \\
0.8,0.7)\end{array}$ & $\begin{array}{l}\text { Uniform distribution between } 0.6 \text { and } 0.8 \text { to reflect customer lead time } \\
\text { valuation }\end{array}$ \\
\hline $\begin{array}{l}\text { Customer variety valuation } \\
\qquad(\theta)\end{array}$ & $\begin{array}{l}\text { RANDOM UNIFORM } \\
(0.5,0.7,0.6)\end{array}$ & $\begin{array}{l}\text { Random uniform distribution between } 0.5 \text { and } 0.7 \text { to reflect the customer } \\
\text { variety valuation }\end{array}$ \\
\hline $\begin{array}{l}\text { Current production rate } \\
\quad(\mathrm{CPR})\end{array}$ & 80 products/month & \\
\hline Platform life (PL) & 36 months & Average life of panel furniture \\
\hline $\begin{array}{l}\text { Platform reconfiguration time } \\
\text { (PRT) }\end{array}$ & 1 month & $\begin{array}{l}\text { Modular platforms are used. This is the time used by the flexible system to } \\
\text { switch from one furniture family to the other }\end{array}$ \\
\hline $\begin{array}{l}\text { Demand smoothing time } \\
\text { (DST) }\end{array}$ & 3 months & Demand smoothing policy \\
\hline$\alpha$ linear function parameter & 1 & Direct relation between PSE and PDR \\
\hline $\begin{array}{l}\text { Cost of variety enabling } \\
\text { technology (ACPR) }\end{array}$ & $\$ 10,000$ & This is the cost to sustain the implemented FMS technology \\
\hline Average Product unit cost & $\$ 50 /$ part & Labour and material (ACPR) \\
\hline $\begin{array}{l}\text { Cost of scalability enabling } \\
\text { technology (ACPR) }\end{array}$ & $10 \%$ of PUC & $\begin{array}{l}\text { Depending on capacity type (which is increase in No. of workers in this } \\
\text { case) }\end{array}$ \\
\hline Simulation time & 60 months & Sufficient horizon for strategic analysis \\
\hline
\end{tabular}

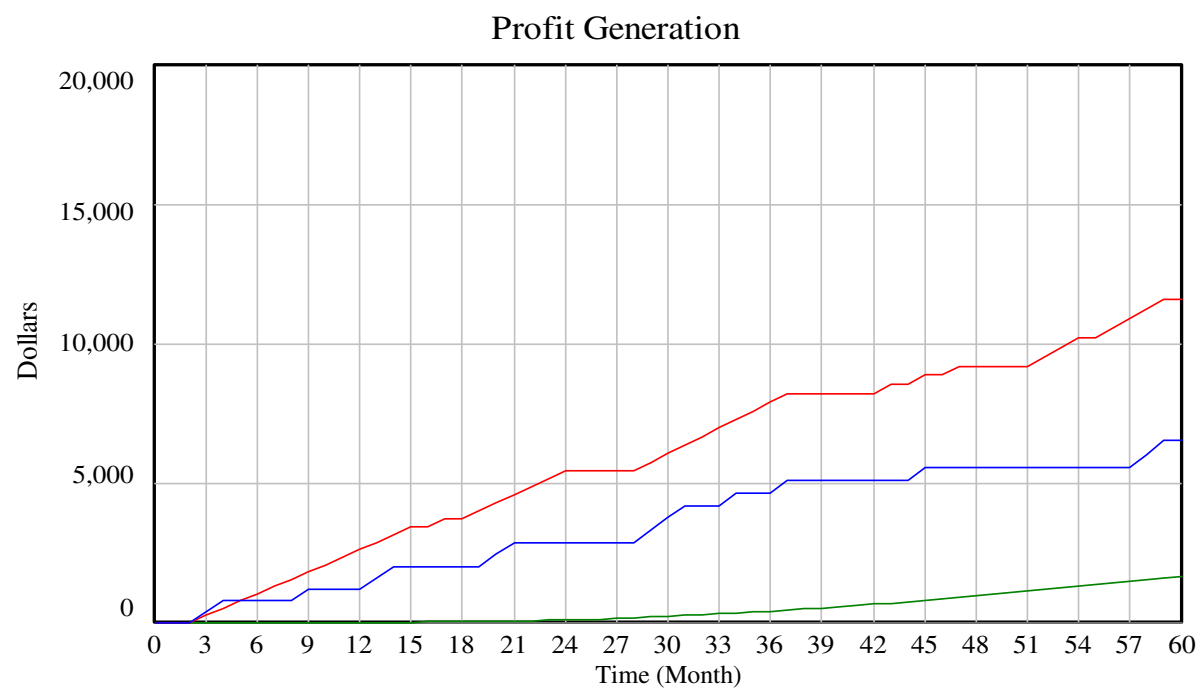

Profit Generation : IVT 4month

Profit Generation : IVT 3month

Profit Generation : IVT 2month

Profit Generation : IVT 1month

Figure 3. Impact of the variety management marketing policy on profit generation.

\subsection{Impact of platform reconfigurability on AAMT variety management}

The next analysis will focus on the impact of platform reconfigurability level and its flexibility on the internal AAMT variety management of the production system, production stability and how it relates to the profit generation in this case study. The reconfigurability of the platform is reflected in PRT parameter. Both aspects are shown in Figure 4(a) and (b) and are analysed as follows.

Figure 4(a) outlines that with short PRT, the APVM levels show more fluctuating behaviour. Lower PRT values will enable manufacturers to have faster and more frequent platform reconfiguration; however, this comes at the expense of 


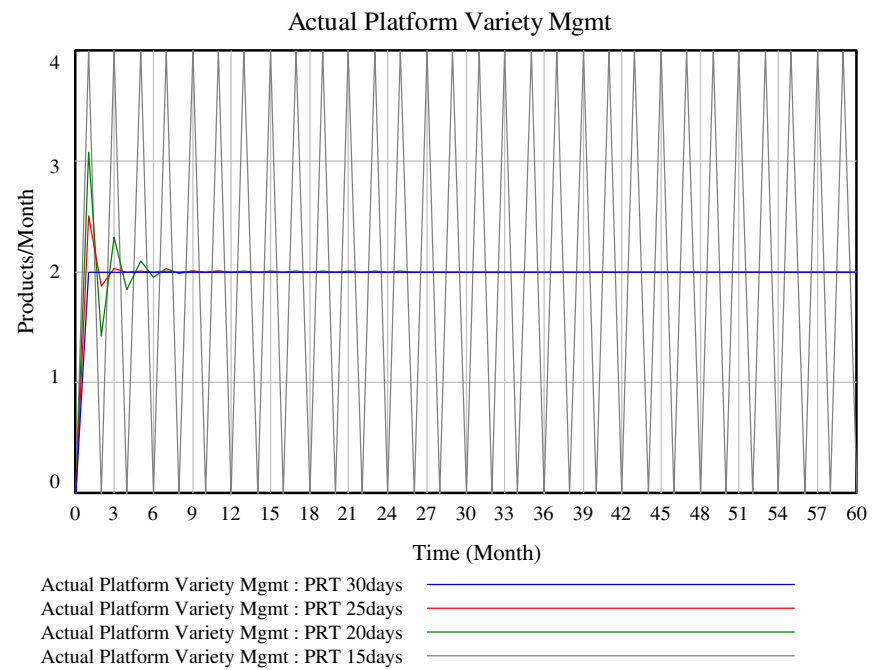

(a)

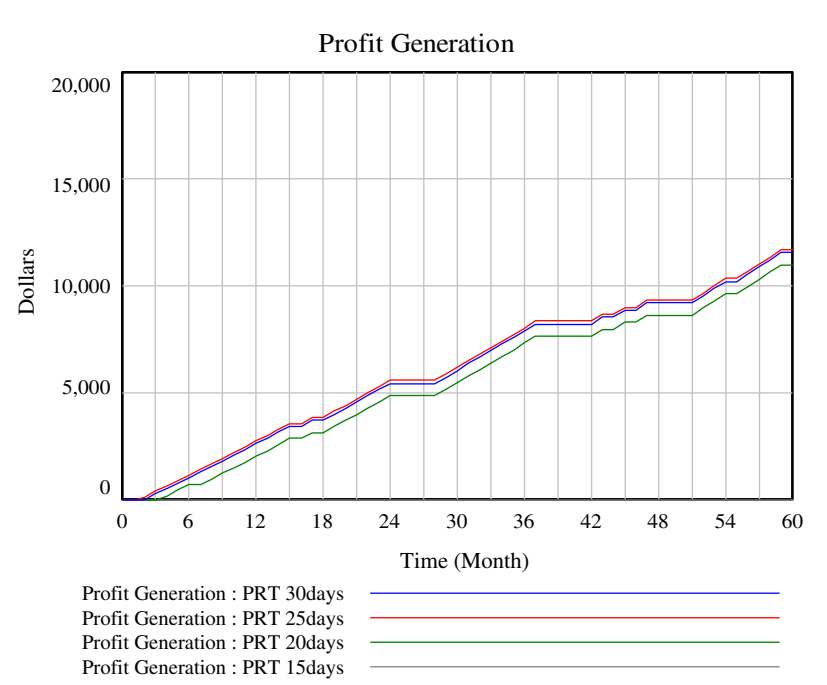

(b)

Figure 4. The impact of PRT on (a) APVM levels and (b) profit generation.

extensive sustaining and management effort as well as less stability. The difference in APVM levels between PRT of 15 days and 30 days in terms of magnitude and dynamics is so significant that the tempting $50 \%$ reduction in reconfiguration time would make production managers more cautious about such flexibility. In the general AAMT context, this aligns with the conflict between over-flexibility and complexity in manufacturing system.

The impact of such dynamic interaction is further illustrated in Figure 4(b) where the highest generated profit was at PRT value of 25 days followed by PRT of 30 days then PRT value of 20 days while there was almost no profit generation with PRT value of 15 days. Within the given case study settings, the balance point between the benefit of fast and frequent response to changes in customer variety scope and the costs of handling the effort and the dynamics associated with such responses was PRT value of 25 days. The costs to handle the very fluctuating behaviour of APVM at PRT value of 15 days exceeded the revenue generated from the faster and full response to the DVS leading to no profit generation. Higher valuation of variety scope satisfaction as well as cheaper technology can alter these results; however, the balance between flexibility and complexity costs will still hold

\subsection{Impact of PL-time on profit generation}

Another important parameter in the AAMT variety management decision is the expected life-cycle of the produced parts family. This parameter is captured in the developed model through the decision on the product PL-time. Manufacturers will use PL-time for the depreciation accounting which contributes to the cost of variety management. Managing the depreciation rate of the product platform directly affects efforts to sustain it. Such effort is also related to the platform type and technology which is captured in the proposed model as CVET. Figure 5 plots the profit generated in the considered case study with different PL-time at low and high CVET values.

Results of the above figure illustrates that higher profit is generated with longer PL-time at both expensive and less expensive variety enabling technologies. The traditional intuition would have expected that shorter PL-time should generate more profit as a result of generating more customer value due to more dynamic market variety performance. However, this is shown to be highly related to the adopted technology that will enable such performance and its cost. Figure 5 raises an important question: In the context of AAMT, how to balance between market pressure to shorten the life cycle of the product families and the internal pressure of the system to stabilise production over extended periods. In the adopted case study, the later pressure superseded the market one.

Furthermore, in addition to having higher profit at lower level of variety enabling technology in general, it was also shown by comparing Figure 5(a) and (b) that at higher technology costs, short PL-time will lead to far less profit than their longer PL at lower technology cost. This confirms that when the market dictates shorter life cycle of products, manufacturers should strive to adopt cheaper variety enabling technologies to stay competitive 


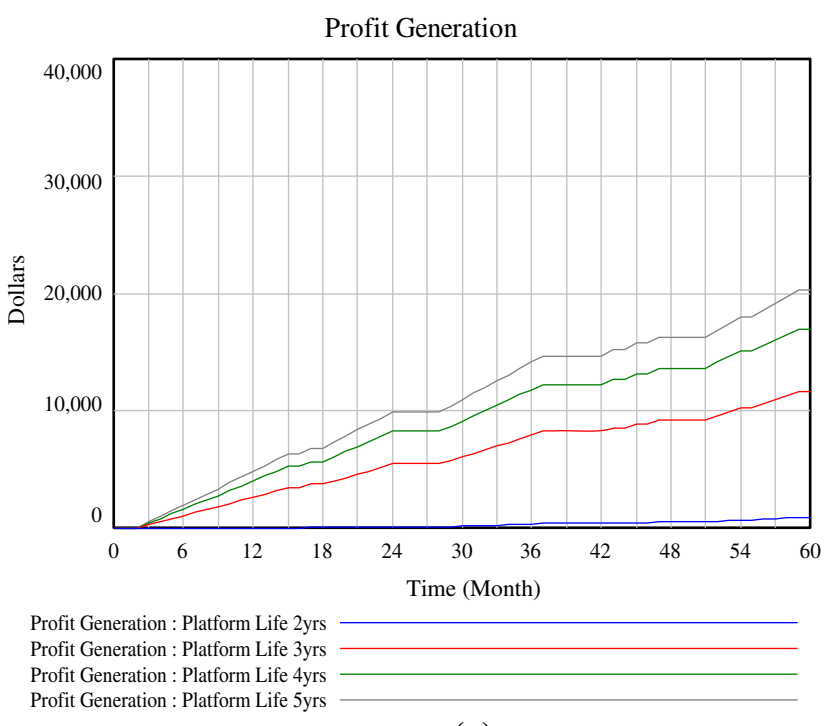

(a)

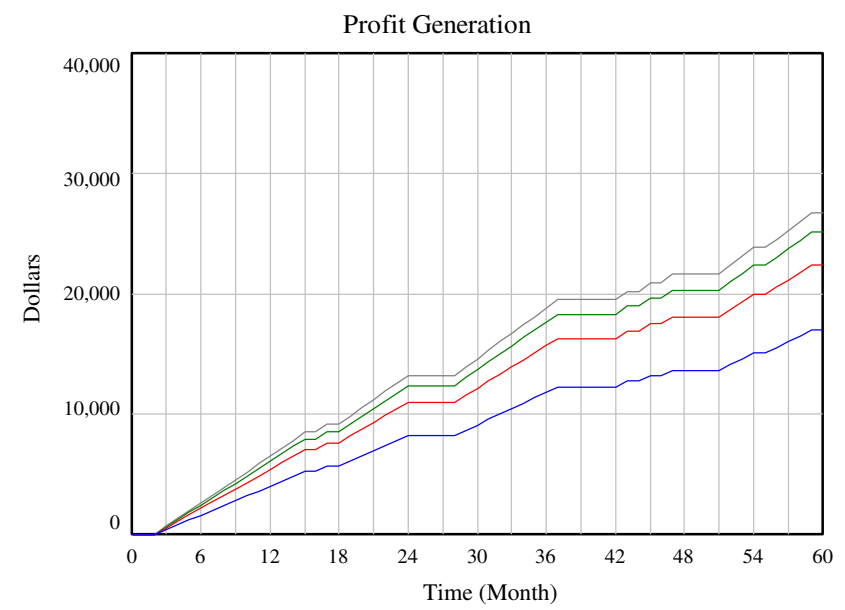

Profit Generation : Platform Life 2yrs

Profit Generation : Platform Life 3yrs

Profit Generation : Platform Life 4yrs

Profit Generation : Platform Life 5yrs

Figure 5. Impact of PL time on profit generation at CVET (a) $\$ 10,000$ (b) $\$ 5000$.

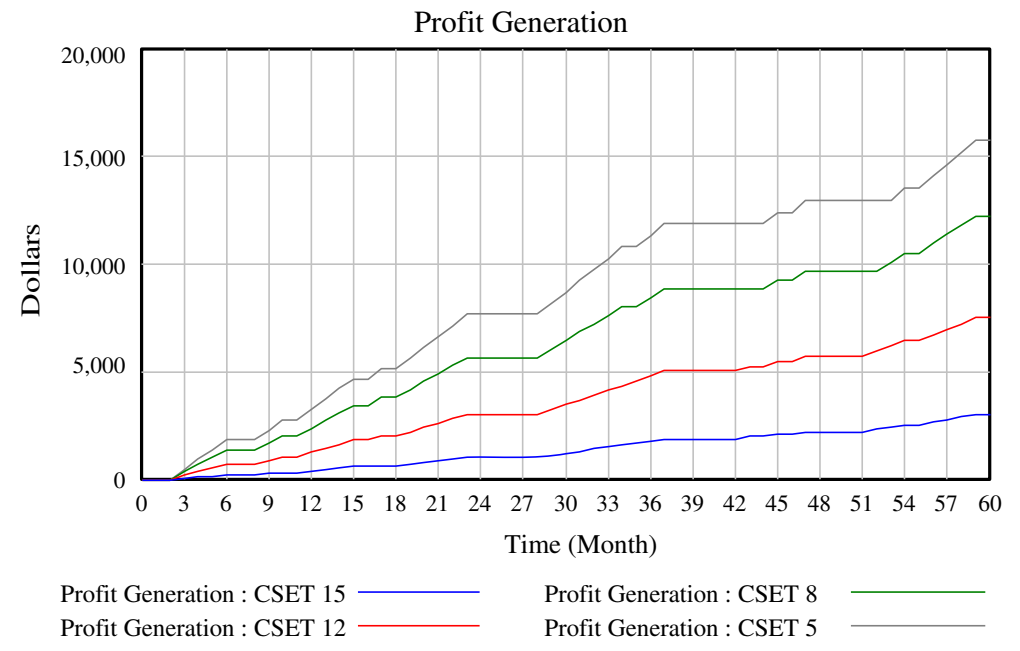

Figure 6. Impact capacity scalability enabling technology on profit generation.

\subsection{Impact of scalability enabling cost on profit generation}

To further investigate the AAMT volume management dynamics in value generation, the impact of CSET cost on profit generated is examined. Figure 6 shows the different profit with different CSET costs pooled over each produced piece of furniture.

Successful implementation of AAMT dynamic capacity will enable the company to manage the required demand volume while maintain the important customers expected LTSL. Another aspect of that service level would be the time required for this successful implementation to occur (scalability delay). Both aspects would improve with more investments in AAMT CSET, but again with an associated cost. In Figure 6 more profit is generated with cheaper CSET values per produced product. This means that in the adopted case study, more investment in scaling capacity did not help much in improving the profit as cheaper technology (increasing working shifts for example rather increasing number of machines) was sufficient to meet the required market valuation for the LTSL. Higher customer valuation values and different system's settings can change such result, however, the trade-off analysis will still hold between effective and efficient capacity scalability management mechanisms. In addition, it is clear that accurate information about the market 
LTSL valuation can help in deciding the best level of CSET. The cost of capturing such information can be well justified by the savings the manufacturer can achieve by avoiding unnecessary investment in production volume scaling technology

\section{Summary and discussion}

Managing the impact of AAMT variety and volume dynamics on cost of production and customer value generation is of prime importance for any business to survive in a competitive and complex market environment. This is because cost and values are part of the key performance indicators needed in the determination of efficiency and profitability of every business. This paper focused on understanding the dynamics of variety and volume management to create value in changeable systems implementing AAMT of reconfigurable platforms and scalable capacities. This understanding was made possible to AAMT managers through dynamically capturing the structure (or design) of these systems and its parameters settings (operating policies). Thus the contributions of the approach can be summarised in relation to these two aspects.

On the structure aspect, multiple dynamics factors impacting the cost and value in changeable manufacturing systems with AAMT were modelled using SD modelling techniques. Through the application of these techniques:

(1) Key variety and volume management dynamics were captured and their causal impact on cost and customer value generation was determined.

(2) A new approach to cost and value modelling in changeable AAMT systems was demonstrated. The unique advantage of this approach is that cost and customer value are not assumed but are derived from quantitative causal variables.

(3) A new approach for value generation is presented. This is not based only on internal manufacturing practices, but also on capturing external market conditions.

On the AAMT management polices aspect, the presented model and parametric analysis developed several interesting insights which can provide useful guidelines to AAMT managers and platform technologies designers in this context. These insights are summarised as follows:

(1) Multiple trade-off decisions are required when deciding on the variety management policy to be adopted by the manufacturers to respond to the required DVS. The analysis showed that the demand smoothing decision (which is a fundamental parameter in setting market-manufacturing response policies and targets) has to recognise that the cost and effort encountered to quickly respond to required variety scope can outperform value created by this fast response. Such insight has its impact on deciding which type of AAMT to adopt in order to maintain the required flexibility.

(2) In addition, reported results of the case study formalised the notion that higher degree of product platforms flexibility is not necessarily the best option when selecting the product platform capabilities. Depending on the customer valuation of variety as well as internal variety management cost, the question of how much AAMT flexibility is needed will be optimally answered.

(3) The adopted AAMT to manage variety and/or volume has a significant impact on the profitability of manufacturing system. Results demonstrated that without higher customer valuation to responsive manufacturers, investment in variety and volume AAMT may be questionable. This also highlights the importance of the continuous effort to make such technologies more cost-effective for today's dynamic market.

(4) Counter to the expected intuition, and within the simulated settings, shorter life cycle of products did not lead to higher profitability levels. The direct dependency between the product life cycle and its product PL time with its associated sustaining and changing costs should direct marketing and AAMT manufacturing planners to have a balanced decision concerning setting the product life cycle and the rate of new products introduction to market.

(5) The value of market information was well demonstrated as it assists in deciding on the required investments in different changeability enabling technologies as well as in the internal planning for variety and volume management settings. The savings realised from the availability and use of this information can payoff for the cost required to attain it.

The developed model and the provided insights will support manufacturers utilising AAMT to understand the different interactions and dynamics between different systems components and their role in value generation to meet demanded variety and volume. Such understanding will aid managers in selecting appropriate AAMT, setting profitable operating polices and determining the best responsiveness level, degree of flexibility, products life span and AAMT investments in changeability technologies. However, there are more dimensions that need to be considered to improve 
the management of production volume and product variety in such systems. It would be interesting to investigate the extent to which the reported results would change with different customer valuation profiles as well as investigate further the enabling technologies relation to system performance. Furthermore, the specific application presented in this paper (with some of its deterministic values) can impose some limitation on the generality of the provided recommendations and thus future work will include more applications to other industries to address such limitation and capture more uncertainty.

In conclusion, the developed systems dynamics model (which combines for the first time the dynamic interactions between customer value satisfaction and dynamic production mix and volume) can be a valuable tool to investigate different management policies in similar demand scenarios as well as many other AAMT systems leading to improved competitiveness.

\section{Acknowledgment}

This research has been supported by the Canada Research Chairs (CRC) programme and the Natural Sciences and Engineering Council (NSERC) of Canada and was conducted at the Intelligent Manufacturing Systems (IMS) Centre at the University of Windsor in Canada.

\section{Disclosure statement}

No potential conflict of interest was reported by the authors.

\section{References}

Adner, R., and D. Levinthal. 2001. "Demand Heterogeneity Technology Evolution: Implications for Product \& Process Innovation." Management Science 47 (5): 611628.

Agyapong Kodua, K., and R. H. Weston. 2011. "Systems Approach to Modelling Cost and Value Dynamics in Manufacturing Enterprises." International Journal of Production Research 49 (8): 21432167.

Asl, R., and A. Ulsoy. 2002. "Capacity Management via Feedback Control in Reconfigurable Manufacturing Systems." Proceeding of Japan USA symposium on Flexible Manufacturing Automation, Hiroshima, Japan.

Boucekkine, R., F. del Rio, and B. Martinez. 2009. "Technological Progress, Obsolescence, and Depreciation." Oxford Economic Papers 61 (3): 440466.

Chambers, C., P. Kouvelis, and J. Semple. 2002. "Quality based Competition, Profitability and Variable Costs.” Management Science 52 (12): 18841895.

Choudhary, V., A. Ghose, T. Mukhopadhyay, and R. Uday. 2005. "Personalized Pricing and Quality Differentiation." Management Science 51 (7): 11201130.

Cooper, R., and S. Kaplan. 1991. The Design of Cost Management Systems: Text, Cases and Readings. Englewood Cliffs, NJ: Prentice Hall.

De Groote, X. 1994. "Flexibility and Marketing/Manufacturing Coordination.” International Journal of Production Economics. $36: 153$ 167.

Deif, A., and W. ElMaraghy. 2006. "A Control Approach to Explore the Dynamics of Capacity Scalability in Reconfigurable Manu facturing Systems." Journal of Manufacturing Systems. 25 (1): 1224.

Deif, A., and H. ElMaraghy. 2007. "Assessing Capacity Scalability Policies in RMS Using System Dynamics.” International Journal of Flexible Manufacturing Systems 19 (3): 128150.

Deif, A., and H. ElMaraghy. 2009. "Modelling and Analysis of Dynamic Capacity Complexity in Multi stage Production." Production Planning \& Control 20 (8): 737749.

Desai, P., S. Kekre, S. Radhakrishnan, and K. Srinivasan. 2001. "Product Differentiation and Commonality in Design: Balancing Revenue and Cost Drivers." Management Science 47 (1): 3751.

Duffie, N., 2014. "Control Theoretical Modeling of Transient Behavior of Production Planning and Control: A Review" Key Note Paper. Proceedings of the 47th CIRP conference on Manufacturing Systems, Windsor, Canada.

ElMaraghy, H. 2005. "Flexible and Reconfigurable Manufacturing Systems Paradigms." International Journal of Flexible Manufactur ing Systems 17 (4): 261276.

ElMaraghy, H., T. AlGeddawy, A. Azab, and W. ElMaraghy. 2011. "Change in Manufacturing Research and Industrial Challenges". 4th International Conference on Changeable, Agile, Reconfigurable and Virtual Production (CARV), Montreal, Canada.

ElMaraghy, H., G. Schuh, W. ElMaraghy, F. Piller, P. Schonsleben, M. Tseng, and A. Bernard. 2013. "Product Variety Management." CIRP Annals 62 (2): 629652.

Gabszewicz, J., and J. Thisse. 1979. "Price Competition, Quality and Income Disparities." Journal of Economic Theory. 20 : 340 359.

Goncalves, P., J. Hines and J. Sterman. 2005. "The Impact of Endogenous Demand on Push Pull Production Systems." System Dynamics Review 22 (3): 217247.

Heese, H., and J. Swaminathan. 2006. "Product Line Design with Component Commonality and Cost reduction Effort." Manufacturing \& Service Operations Management. 8 (2): 206219. 
Hu, J., J. Ko, L. Weyand, H. ElMaraghy, T. Lien, Y. Koren, Y. Koren, et al. 2011. “Assembly System Design and Operations for Product Variety" CIRP Annals Manufacturing Technology 60 (2): 715733.

Jianxin, J., and M. Tseng. 2000. "Fundamentals of Product Family Architecture.” Integrated Manufacturing Systems 11 (7): 469483.

Jiao, J., and T. Simpson, and Z. Siddique. 2007. "Product Family Design and Platform Based Product Development: A State of the art Review." Journal of Intelligent Manufacturing 18 (1): 529.

Jones, R., and H. Mendelson. 2011. "Information Goods vs. Industrial Goods: Cost Structure and Competition.” Management Science 57 (1): 164176.

Khataie, A., and A. Bulgak. 2013. "A Cost of Quality Decision Support Model for Lean Manufacturing: Activity based Costing Application." International Journal of Quality and Reliability Management. 30 (7): 751764.

Kim, K., and D. Chhajed. 2000. "Commonality in Product Design: Cost Saving, Valuation Change and Cannibalization." European Journal of Operational Research 125 (3): 602621.

Krishnan, V., and W. Zhu. 2006. "Designing a Family of Development intensive Products." Management Science 52 (6): 813825.

Lopez, P., and A. Arbos. 2013. "Lean Manufacturing: Costing the Value Stream." Industrial Management and Data Systems. 113 (5): 647668.

Luss, H. 1982. “Operations Research and Capacity Expansion Problems: A Survey.” Operations Research 30 (5): 907947.

Manne, A. 1967. Investments for Capacity Expansion, Size, Location, and Time phasing. Cambridge, MA: The MIT Press.

Martínez Olvera, C., and Y. Davizon Castillo. 2015. "Modeling the Supply Chain Management Creation of Value A Literature Review of Relevant Concepts". http://dx.doi.org/10.5772/59656.

Marufuzzaman, M., and A. Deif. 2010. "A Dynamic Approach to Determine the Product Flow Nature in Apparel Supply Chain Network." International Journal of Production Economics Special Issue on Supply Chain Forecasting 128: 484495.

Matsubayashi, N., Y. Ishii, K. Watanabe, and Y. Yamada. 2009. "Full line or Specialization Strategy? The Negative Effect of Product Variety on Product Line Strategy." European Journal of Operational Research 196 (2): 795807.

Matta, A., M., Tomasell, and A. Valente. 2007. "Impact of Ramp up on the Optimal Capacity related Reconfiguration Policy." International Journal of Flexible Manufacturing Systems 19 (3): 173194.

Matta, A., M. Tomasell, M. Clerici, and S. Saconi. 2008. "Optimal Reconfiguration Policy to React to Product Changes." International Journal of Production Research 46 (10): 26512673.

Miller, S. 1999. "VW Struggles with Look alike Brands." Wall Street Journal (Nov. 1) M2.

Mussa, M., and S. Rosen. 1978. "Monopoly and Product Quality.” Journal of Economy Theory 18: 301317.

Park, J., and W. Simpson. 2008. "Toward an Activity based Costing System for Product Families and Product Platforms in the Early Stages of Development." International Journal of Production Research 46 (1): 99130.

Piller, F., and F. Salvador. 2013. "Design Toolkits, Organizational Capabilities, and Firm Performance." In Revolutionizing Innovation: Users, Communities, and Open Innovation, edited by D. Harhoff and K. Lakhani, 483 509. Cambridge, MA: MIT Press.

Putnik, C., A. Sluga, H. ElMaraghy, R. Teti, Y. Koren, T. Tolio, and B. Hon. 2013. "Scalability in Manufacturing Systems Design and Operation: State of the art and Future Developments Roadmap." CIRP Annals 63 (2): 124.

Ramdas, K. 2003. "Managing Product Variety: An Integrative Review and Research Directions." Production Operation Management 12 (1): 79101.

Richardson, G. 1996. Modelling for Management: Simulation in Support of Systems Thinking. Aldershot: Dartmouth Publishing Company.

Ross, A., D. Rhodes, and D. Hastings. 2008. "Defining Changeability: Reconciling Flexibility, Adaptability, Scalability, Modifiability, and Robustness for Maintaining System Lifecycle Value.” Systems Engineering. 11 (3): 246262.

Schmidt, G., and E. Porteus. 2000. "The Impact of an Integrated Marketing and Manufacturing Innovation." Manufacturing \& Service Operations Management. 2 (4): 317336.

Spicer, P., Y. Koren, M. Shpitalni, and D. Yip Hoi. 2002. "Design Principles for Machining System Configurations." CIRP Annals Manufacturing Technology 51 (1): 105108.

Spicer, P., D. Yip Hoi, and Y. Koren. 2005. "Scalable Reconfigurable Equipment Design Principles." International Journal of Production Research 43 (22): 48394852.

Sterman, J. 2000. Business Dynamics: Systems Thinking and Modeling for a Complex World. Boston, MA: McGraw Hill.

Suzić, N., B. Stevanov, I. Ćosić, Z. Anišić, and N. Sremčev. 2012. "Customizing Products through Application of Group Technology: A Case Study of Furniture Manufacturing.” Journal of Mechanical Engineering 58 (12): 724731.

Tirole, J. 1988. The Theory of Industrial Organization. Cambridge, MA: MIT Press.

Vandenbosch, M., and C. Weinberg. 1995. "Product and Price Competition in a Two dimensional Vertical Differentiation Model." Marketing Science 14 (2): 102117.

Vlachos, D., P. Georgiadis, and E. Iakovou. 2007. “A System Dynamics Model for Dynamic Capacity Planning of Remanufacturing in Closed loop Supply Chains.” Computers \& Operations Research 34: 367394.

Wikner, J., M. Naim, and M. Rudberg. 2007. "Exploiting the Order Book for Mass Customized Manufacturing Control Systems with Capacity Limitations." IEEE Transactions on Engineering Management 54 (1): 145155.

Wolstenholme, E. 1999. "Qualitative Vs Quantitative Modelling: The Evolving Balance." Journal of the Operational Research Society 50: 422428.

Yu, D. 2012. "Product Variety and Vertical Differentiation in a Batch Production System." International Journal Production Economics 138: 314328 . 